\title{
Improvement of Engineering Properties of Residual Soil of Tuff Breccia by Electro-Kinetic Method
}

\author{
Hnin Thazin Aung ${ }^{1}$, Doni Prakasa Eka Putra ${ }^{* 2}$, and I Gde Budi Indrawan ${ }^{2}$ \\ ${ }^{1}$ Department of Geology, Dagon University, Myanmar \\ ${ }^{2}$ Department of Geological Engineering, Faculty of Engineering, Gadjah Mada University, Yogyakarta, Indonesia
}

\begin{abstract}
This paper presents the results of an experimental study that was conducted to improve engineering properties of residual soil of tuff breccia by applying the electrokinetic method. The soil samples were taken from a slope in a high susceptible landslide area in the Kulon Progo, Yogyakarta, Indonesia. The electro-kinetic experiments were conducted using a clear glass tank of $60 \mathrm{~cm} \times 30 \mathrm{~cm} \times 30 \mathrm{~cm}$ size, a $13 \mathrm{~V}$ power pack to supply the voltage, and aluminum electrodes. The results showed that the $\mathrm{pH}$ value of anolyte decreased while that of catholyte increased during the treatment. The Atterberg's limits of all soil samples decreased, while the shear strengths increased. XRD and SEM analyses indicated that there were no mineral changes after electro-kinetic experiments. However, the soil structure changed and became denser. The increased soil strength after electro-kinetic treatment would likely improve stability of natural slopes.
\end{abstract}

Keywords: Electro-kinetic · Soil improvement - Slope stability · Tuff breccia.

\section{INTRODUCTION}

Electro-kinetic is defined as the physicalchemical transport of charge, action of charged particles, and effects of applied electric potentials on formation and fluid transport in porous media under an applied electric current (Alshawabkeh, 2001). Electro-kinetic phenomena results from the differential movement of two phases, which are solid and liquid phases, where the interface is an electrical double layer. There are four electro-kinetic phenomena; electro-osmosis, electro-migration, electrophoresis and steaming potential. Referring to Rustamaji (2007), due to the electric field that is induced through adjacent electrodes, cations in the anolyte will move toward the cathode in the same direction due to both of electro osmosis and electro migration. On the other hand, the direction of anion transport is in the reverse direction of cation transport so that anion will move from the cathode to anode by the electro

\footnotetext{
${ }^{*}$ Corresponding author: D.P.E. PUTRA, Department of Geological Engineering, Gadjah Mada University. Jl. Grafika 2 Yogyakarta, Indonesia. E-mail: putra_dpe@yahoo.com
}

migration mechanism. When anions are placed in anolyte, they will be transported by electro osmosis from the anode toward the cathode. In electro osmosis, electrolysis of water at the anode and the cathode produces oxygen and hydrogen, respectively, which can be represented by Equations (1) and (2), as follows:

$$
\begin{array}{r}
2 \mathrm{H}_{2} \mathrm{O}-4 \mathrm{e}^{-} \rightarrow 4 \mathrm{H}^{+}+\mathrm{O}_{2} \text { anode } \\
2 \mathrm{H}_{2} \mathrm{O}+2 \mathrm{e}^{-} \rightarrow 2 \mathrm{OH}^{-}+\mathrm{H}_{2} \uparrow \quad \text { cathode }
\end{array}
$$

The electrolysis reaction describes that acid will be generated at the anode side, while at the cathode side, alkaline will be produced (Equation (2)). Therefore, the $\mathrm{pH}$ value decreases at the anode but increases at the cathode. Propagation of acid and base fronts promote the dissolution of ions (or metal ions) near the anode and precipitation of the ions (or metal ions) near the cathode. The changes of physiochemical properties of the soil are different during electro-kinetic stabilization when admixtures are added to the soil, in which case the changes in behavior of the soil occurs through cementation or pozzolanic reactions (Nasim et 
al., 2012). By the addition of an appropriate enhancement agent, such as lime or calcium chloride, some properties of the soil such as texture, plasticity, compressibility and permeability will be altered; therefore, they can be very effective in improving soil characteristics by reducing the amount of clay size particles and increasing the shear strength (Nasim et al., 2012). When cations are used as stabilizing agents, ions migrate into soils through processes of electro-migration and electro-osmosis. These ions improve the soil strength by three mechanisms, namely cation exchange, mineralization, and precipitation of species in the pore fluid (Thakur et al., 2011).

It is precipitation or mineralization that provides the greatest contribution to increase in strength. However, this type of reaction usually occurs when $\mathrm{pH}$ values of the soil solution are greater than seven. The soil improvement during electro-kinetic stabilization can occur due to the electro osmotic consolidation or electrochemical changes such as pozzolanic reactions that lead to cementation of soil and the changes of mineral, resulting in the soil strengthening (Malekzadeh, 2016). In addition, the dissociation of calcium chloride and water results in increased concentrations of $\mathrm{Ca}^{2+}$ and $\mathrm{OH}^{-}$, which accounts for the rise in $\mathrm{pH}$ value of the pore water. The strongly alkaline condition promotes the dissolution of silica $\left(\mathrm{SiO}_{2}\right)$ and alumina $\left(\mathrm{Al}_{2} \mathrm{O}_{3}\right)$ from soil, which then gradually react with the $\mathrm{Ca}^{2+}$ ions, forming the secondary cementitious products, namely calcium silicate hydrate and calcium alumina hydrate, which hardened when cured to treat the soil (Justin and Robert, 2004).

Black and Wektman (2010) successfully stabilized a Victorian railway embankment in London by usingelectro-kinetic method. The embankment was $9 \mathrm{~m}$ high with $22^{\circ}$ side slopes and was constructed by a mixture of London clay and brick fragments, overlying alluvium and terrace gravel. After soil treatments, the application of direct current, electrical potential was created and caused the water transported from cathode to anode. The difference of electrical potential $(60-80 \mathrm{~V})$ across the slope become the water to be drained away from cathode and lead to consolidation and increase in shear strength of the slope materials. The result also indicated that $75 \%$ increase in the factor of safety as a result of the electro-kinetic stabilization.

This research was conducted to improve engineering properties of residual soil of tuff breccia by applying the electro-kinetic method. The mineralogical properties of the residual soil prior to and after the electro-kinetic experiments were investigated to understand the factors causing the change of the soil engineering properties. Slope stability analyses were performed to assess the changes in the safety factors of natural slopes consisting of soils improved electro-kinetically.

\section{MAterial AND Methods}

Soil samples used for the electro-kinetic experiments were taken from a landslide prone area in Samigaluh Sub-district, Kulon Progo Regency, Yogyakarta Special Region, Indonesia. According to Fauzian (2016), the groundwater table at the hillside of this area ranges from 1 to $3 \mathrm{~m}$ and on the top of the hill is $>3 \mathrm{~m}$.

The electro-kinetic experiments were performed in a clear glass tank of $60 \mathrm{~cm} \times 30 \mathrm{~cm}$ $\times 30 \mathrm{~cm}$ size, $13 \mathrm{~V}$ power pack to supply the voltage, and aluminum electrodes. Two sets of $16 \mathrm{~cm}$ high, $34^{\circ}$ inclination soil slopes were constructed by placing the soil with compaction in the central compartment of the tank to achieve the same density of the natural soil. The angle of experimental slopes simulated the angle of natural soil slope in the field. To prevent the soil particles move to other sides, a cotton filter was used to separate the soil sample from four sides during the movement of water and chemical species. The compartments A and B were filled with tap water, which was used to simulate the groundwater condition in the field, while the two electrode compartments were filled with catholyte and anolyte solutions at a constant level (Figure 1). Two sets of electro-kinetic experiments were conducted where the catholyte compartments were filled with groundwater. In the first experiment, the anolyte compartment was filled groundwater, while in the second experiment the anolyte compartment was filled with calcium chloride, as a chemical solution (Table 1). Two $1 \mathrm{~mm}$ thick of aluminum plates were used as the cathode and anode. The experiments were performed by applying a constant 
electric current DC power supply for the duration of the test. The value of $\mathrm{pH}$ at the anolyte and catholyte were measured every one hour for first 12 hours of the experiment, then every three hours until the following 3 days, after which the measurements were taken every 6 hours. Each of the electro-kinetic experiments were conducted approximately in 6 days. After each experiment, soil samples were taken at three different locations (i.e., near the anode, near the cathode, and in the middle of the soil slope) for tests of soil engineering and mineralogical properties. Soil engineering properties examined prior to and after the electro-kinetic experiments were Atterberg's limits and shear strength. Soil shear strength parameters (i.e., cohesion and internal friction) were determined bydirect shear tests. To investigate the changes of soil fabric or occurringof new mineral due to the effect of cementation and precipitation behavior after electro-kinetic treatment, Scanning Electron Microscopy (SEM) and X-Ray Diffraction (XRD) analyses were conducted.

Slope stability analyses were subsequently performed to assess the changes in the safety factors (Fs) of natural slopes consisting of soils improved electro-kinetically. The slope stability analyses were performed using the ordinary method of slices.

\section{Result AND Discussion}

XRD analyses showed that the residual soil contained several abundant minerals of montmorillonite, halloysite, kaolinite, K-feldspar, and quartz (Figure 2). The sheet-like and platy structures of kaolinite can be seen in the SEM micrograph of the untreated soil (Figure 3).

Table 2 and Table 3 show the Atterberg's limits of the soil samples prior and after the experiments of the $\mathrm{Ca}-\mathrm{Gw}-\mathrm{Cl}$ and $\mathrm{Gw}-\mathrm{Gw}-\mathrm{Cl}$ systems. It is shown that the Atterberg's limits of the soil samples after the electro-kinetic experiments decreased significantly. The electrokinetic experiments also showed that the reduction of plastic and liquid limits of the soil samples in the $\mathrm{Ca}-\mathrm{Gw}-\mathrm{Cl}$ system was more significant than that of the $\mathrm{Gw}-\mathrm{Gw}-\mathrm{Cl}$ systems, although reduction of plasticity index of the soil samples in the $\mathrm{Gw}-\mathrm{Gw}-\mathrm{Cl}$ system was more significant than that of the $\mathrm{Ca}-\mathrm{Gw}-\mathrm{Cl}$ system. The addition of calcium chloride and groundwater at the anode which caused decreasing in Atterberg's limit is due to dissolution of hydrogen and calcium ions and migrate from anode to cathode part.

Soil shear strength is governed by the internal friction angle and cohesion of soil particles. Direct shear strength tests showed that the natural residual soil in the research area typically had a relatively low internal friction angle $\left(11^{\circ}\right)$ but relatively high cohesion $(24 \mathrm{kPa})$. The electrokinetic experiments showed that the internal friction angles of the soil samples decreased, while the cohesions increased after the experiments (Table 4 and Table 5). The volume changing in soil particles and soil structure due to the electrochemical reaction in soil caused the decreasing of the internal friction angle and compaction of soil structure after the electro-kinetic experiments caused the increasing of cohesion of soil.

The addition of calcium ions at the anode part, which then migrated to the cathode, caused ion precipitation resulting in the changes in soil structure due to the electrochemical reaction in soil such as electrolysis, cation exchange and transportation of water. The changes of soil shear strength (Table 4 and Table 5) at the anode and the middle part of the soil were due to the cation exchange of calcium and hydroxide ions that reduced the thickness of double layer and the particles of the soil became densely packed each other. For Gw$\mathrm{Gw}-\mathrm{Cl}$ system, only natural groundwater was applied at both electrodes, therefore no significant increased soil shear strength occurred and only hydrogen ions and hydroxide ions were released in the electrolysis processes. In an alkaline environment, ion precipitation normally occurs and forms a cementing compound that bind the soil particles resulting in increase of soil shear strength under electric field. Under acidic environment, the abundance of hydrogen ions caused the changes of the pore fluid resulting in the changes of soil structure, although no cations, such as calcium, or other ions were introduced into the system (Mosavat, 2014). The results of XRD analyses prior to and after experiments shown in Table 6 and Table 7 indicate that there were no new minerals formed after the electro-kinetic experiments.

In the $\mathrm{Ca}-\mathrm{Gw}-\mathrm{Cl}$ system, the shear strength 


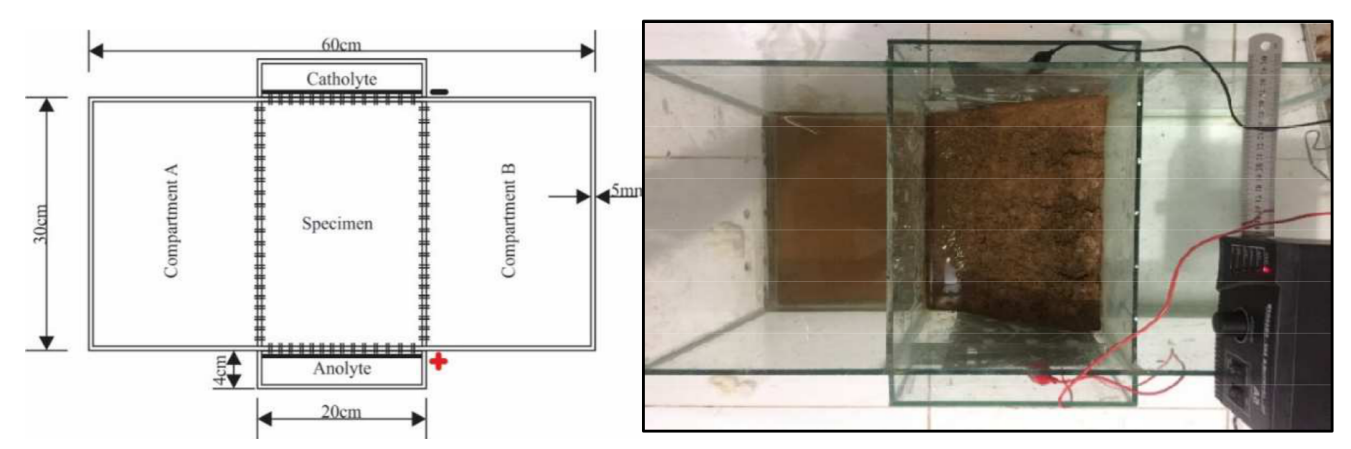

Figure 1. Schematic diagram of the electro-kinetic set-up.

Table 1. Electro-kinetics experiments.

\begin{tabular}{llll}
\hline Anolyte & Catholyte & Water condition & System \\
\hline Groundwater & Groundwater & Constant Level & Gw-Gw-Cl \\
Calcium Chloride & Groundwater & Constant Level & Ca-Gw-Cl \\
\hline
\end{tabular}

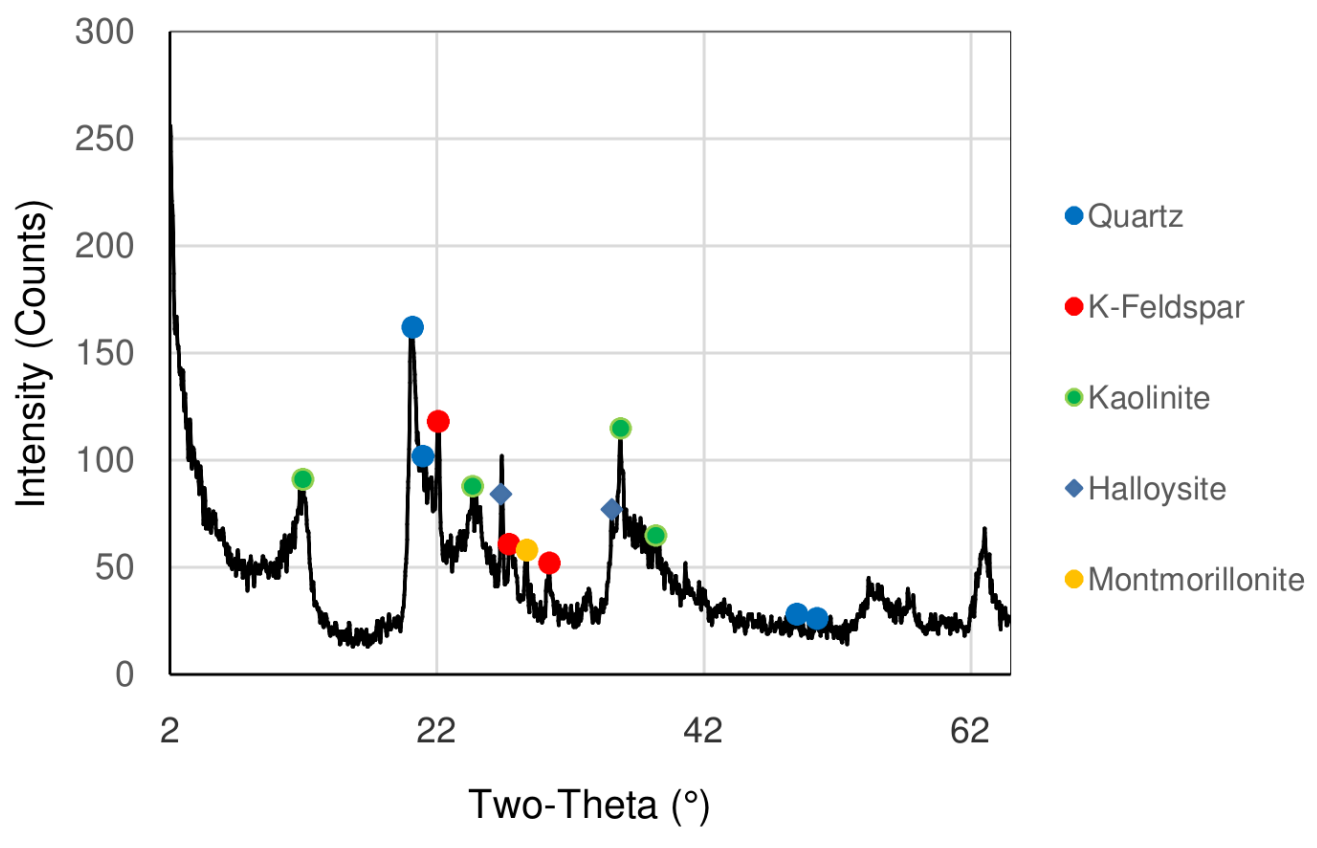

Figure 2. Diffractogram of the untreated soil sample.

Table 2. Atterberg's limits of the soil samples in the $\mathrm{Ca}-\mathrm{Gw}-\mathrm{Cl}$ system.

\begin{tabular}{lccccc}
\hline \multirow{2}{*}{ Parameter } & \multirow{2}{*}{ Untreated soil } & \multicolumn{4}{c}{ Treated soil } \\
& & Anode & Middle & Cathode & Average \\
\hline Liquid Limit (\%) & 56.11 & 41.00 & 37.72 & 38.47 & 39.07 \\
Plastic Limit (\%) & 50.11 & 38.53 & 34.52 & 35.64 & 36.23 \\
Plasticity Index (PI) & 6.00 & 2.47 & 3.21 & 2.84 & 2.84 \\
\hline
\end{tabular}




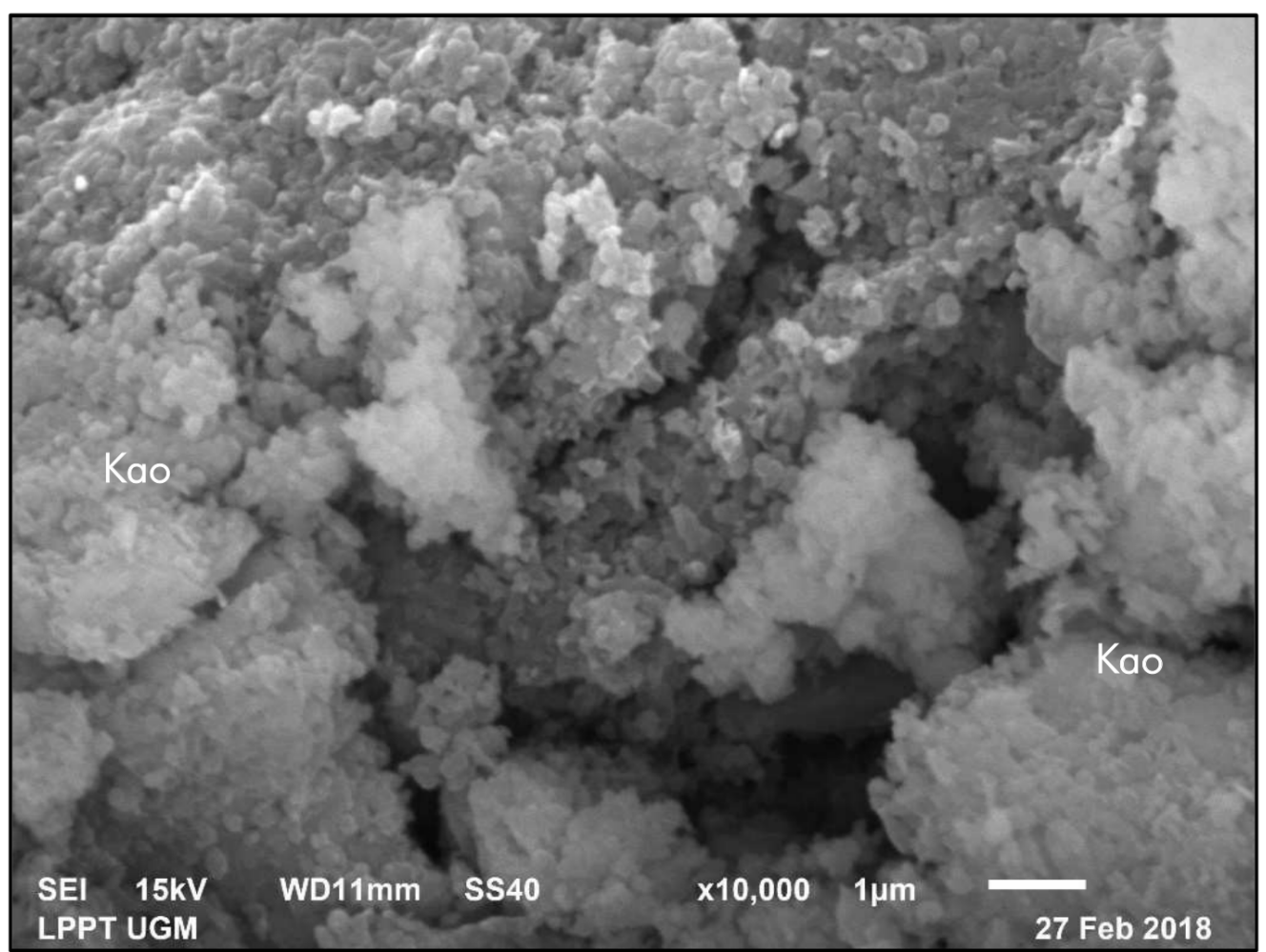

Figure 3. SEM micrograph of the untreated soil sample $(\mathrm{KaO}=$ kaolinite $)$.

Table 3. Atterberg's limits of the soil samples in the Gw-Gw-Cl system.

\begin{tabular}{lccccc}
\hline \multirow{2}{*}{ Parameter } & \multirow{2}{*}{ Untreated soil } & \multirow{4}{c}{ Treated soil } \\
& & Anode & Middle & Cathode & Average \\
\hline Liquid Limit (\%) & 56.11 & 45.21 & 39.19 & 39.73 & 41.38 \\
Plastic Limit (\%) & 50.11 & 41.85 & 37.42 & 38.48 & 39.25 \\
Plasticity Index (PI) & 6 & 3.35 & 1.77 & 1.25 & 2.12 \\
\hline
\end{tabular}

Table 4. Shear strength and shear strength parameters of the soil samples in the Ca-Gw-Cl system.

\begin{tabular}{lccccc}
\hline \multirow{2}{*}{ Parameter } & \multirow{2}{*}{ Untreated soil } & \multicolumn{4}{c}{ Treated soil } \\
& & Anode & Middle & Cathode & Average \\
\hline Cohesion $(\mathrm{kPa})$ & 24 & 59.6 & 56.07 & 64.1 & 59.92 \\
Internal friction $\left(^{\circ}\right)$ & 11 & 6.54 & 10.59 & 5.88 & 7.67 \\
Shear Strength & 34.42 & 66.21 & 66.85 & 70.04 & 67.7 \\
\hline
\end{tabular}

Table 5. Shear strength and shear strength parameters of the soil samples in the Gw-Gw-Cl system.

\begin{tabular}{lccccc}
\hline \multirow{2}{*}{ Parameter } & \multirow{2}{*}{ Untreated soil } & \multirow{4}{c}{ Treated soil } \\
& & Anode & Middle & Cathode & Average \\
\hline Cohesion $(\mathrm{kPa})$ & 24 & 53.31 & 51.5 & 57.79 & 54.2 \\
Internal friction $\left(^{\circ}\right)$ & 11 & 5.21 & 7.85 & 7.06 & 6.71 \\
Shear Strength & 34.42 & 58.57 & 59.45 & 64.93 & 60.98 \\
\hline
\end{tabular}


Table 6. Composition of minerals in the soil samplesin the Ca-Gw-Cl system.

\begin{tabular}{lll}
\hline Ca-Gw-Cl System & Non-clay mineral & Clay mineral \\
\hline Initial Soil & Quartz, K-feldspar & Halloysite, kaolinite, montmorillonite \\
Anode & Quartz, K-feldspar & Halloysite, kaolinite, montmorillonite \\
Middle & Quartz, K-feldspar & Halloysite, kaolinite, montmorillonite \\
Cathode & Quartz, K-feldspar & Halloysite, kaolinite, montmorillonite \\
\hline
\end{tabular}

Table 7. Composition of minerals in the soil samplesin the $\mathrm{Gw}-\mathrm{Gw}-\mathrm{Cl}$ system.

\begin{tabular}{lll}
\hline Gw-Gw-Cl System & Non-clay mineral & Clay mineral \\
\hline Initial Soil & Quartz, K-feldspar & Halloysite, kaolinite, montmorillonite \\
Anode & Quartz, K-feldspar & Halloysite, kaolinite, montmorillonite \\
Middle & Quartz, K-feldspar & Halloysite, kaolinite, montmorillonite \\
Cathode & Quartz, K-feldspar & Halloysite, kaolinite, montmorillonite \\
\hline
\end{tabular}

of the soil at the cathode was the greatest in this experiment. The mineral constituents of the soil samplesdid not change prior to and after the electro-kinetic experiment. However, the structures of the clay minerals were interconnected. Figure 4, Figure 5, and Figure 6 show the images of soil fabrics at the anode, middle, and cathode parts, respectively, in the $\mathrm{Ca}-\mathrm{Gw}-\mathrm{Cl}$ system after the electro-kinetic experiment. At the anode, the clay minerals of kaolinite and montmorillonite appear to be interconnected each other leading to increase in shear strength of the soil samples as a product of cementation due to the cation exchange (electro-migration) and transportation of water (electro-osmosis). At the middle and cathode parts, the platy-structure clay minerals of kaolinite are seen closely connected each other and form aggregates of clay particles leading to an increasedsoil density. Precipitation of calcium compounds $(\mathrm{CAH}=$ Calcium Aluminum Hydrate) due to the pozzolanic reaction likely caused the microscopic structure of soil particles at the cathode to be denser than that at the anode and middle parts of the experimental setup as that gave the greatest shear strength increasing of the soil.

Figure 7, Figure 8, and Figure 9 show micro structures of the soil samples at three different parts in the $\mathrm{Gw}-\mathrm{Gw}-\mathrm{Cl}$ system after the electrokinetic experiment. The clay particles of montmorillonite appear to bind together causing a slight increased shear strength of soil sample at the anode part (Figure 7). At the middle and cathode parts, the platy-structure clay minerals of kaolinite are seen closely combined each
Table 8. Factor of safety of slopes consisting of untreated and treated soil samples.

\begin{tabular}{lc}
\hline Types of sample & Factor of Safety (FS) \\
\hline Untreated soil & 1.75 \\
Ca-Gw-Cl system & 4.49 \\
Gw-Gw-Cl system & 4.07 \\
\hline
\end{tabular}

other causing the soil samples to become denser and to increase the shear strength (Figure 8 and Figure 9). It seems that the groundwater also increased slightly the shear strength of the soil samples under acidic environment due to abundance release of hydrogen ions at the anode and middle parts. At the cathode, precipitation of cations always occurs under the high alkaline environment, leading to the change in the soil structure and increase inthe shear strength.

Results of the slope stability analyses are presented in Table 8. It is shown that safety factors of the slopes increase, particularly after the electro-kinetic treatment with using calcium chloride solution. The increased soil strength after electro-kinetic treatment would likely improve stability of natural slopes.

\section{CONCLUSION}

In this research, electro-kinetic experiments were conducted to improve the engineering properties of residual soil of tuff breccia collected in Kulon Progo, Yogyakarta, Indonesia. The results showed that the $\mathrm{pH}$ value of anolyte decreased while that of catholyte increased during the treatment. The Atterberg's limits of all soil samples decreased, while the shear 


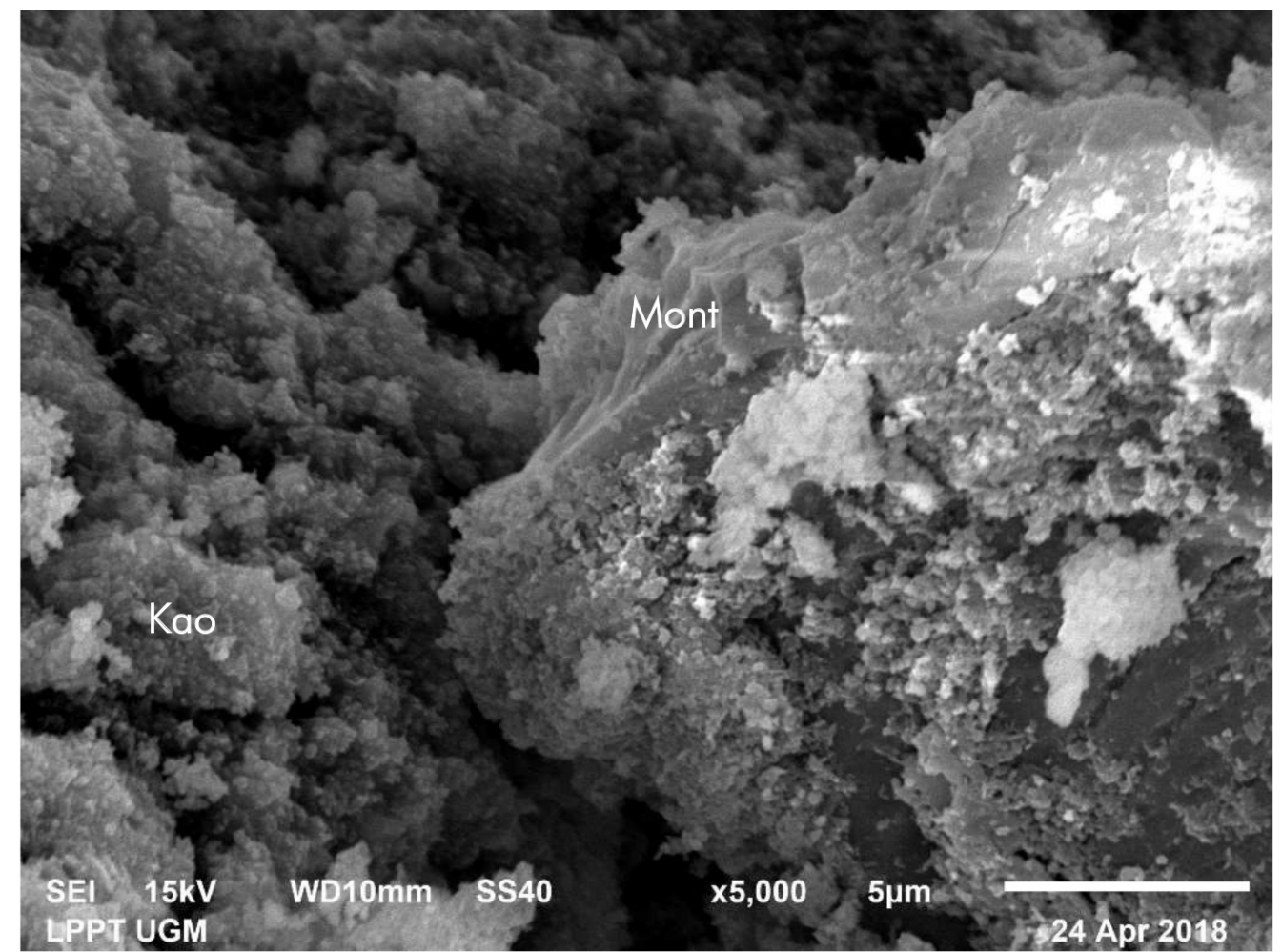

Figure 4. SEM micrograph of the soil samplein the Ca-Gw-Cl system at the anode part (Kao = kaolinite, Mont = montmorillonite).

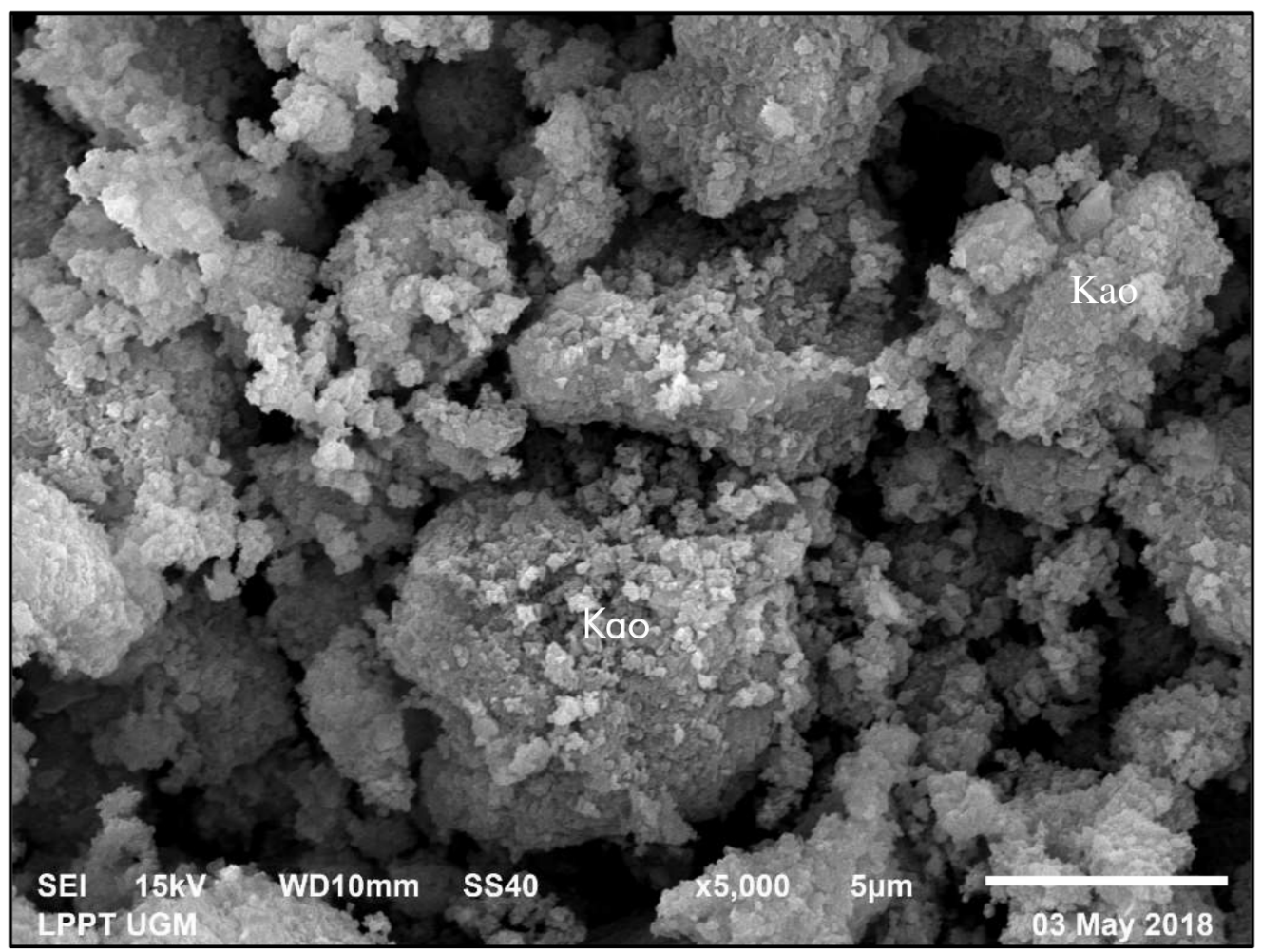

Figure 5. SEM micrograph of the soil sample in the $\mathrm{Ca}-\mathrm{Gw}-\mathrm{Cl}$ system at the middle part $($ Kao $=$ kaolinite). 


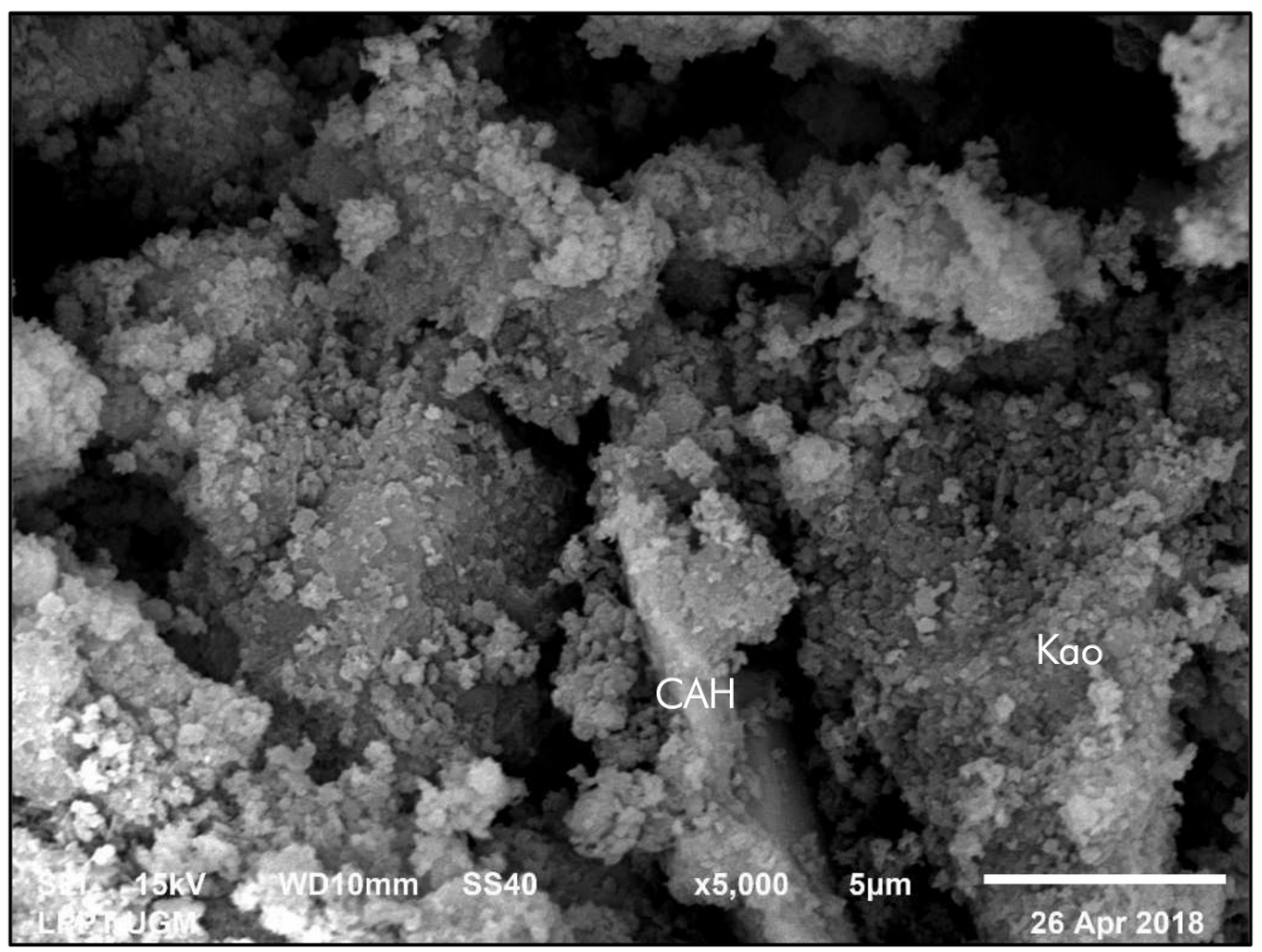

Figure 6. SEM micrograph of the soil sample in the $\mathrm{Ca}-\mathrm{Gw}-\mathrm{Cl}$ system at the cathode part $(\mathrm{Kao}=$ kaolinite, $\mathrm{CAH}=$ calcium aluminum hydrate).

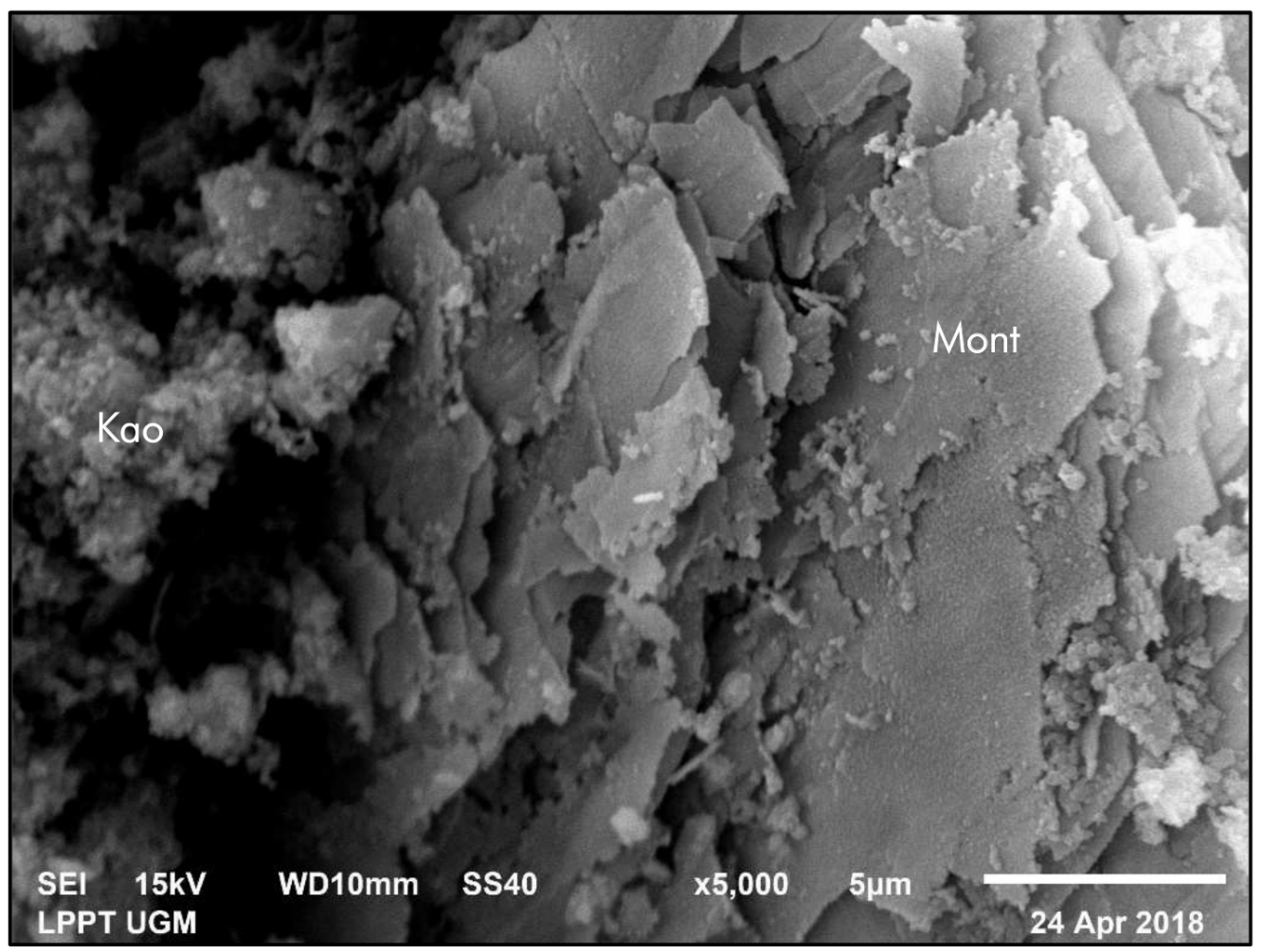

Figure 7. SEM micrograph of the soil sample in the $\mathrm{Gw}-\mathrm{Gw}-\mathrm{Cl}$ system at the anode part (Kao = kaolinite, Mont $=$ montmorillonite) . 


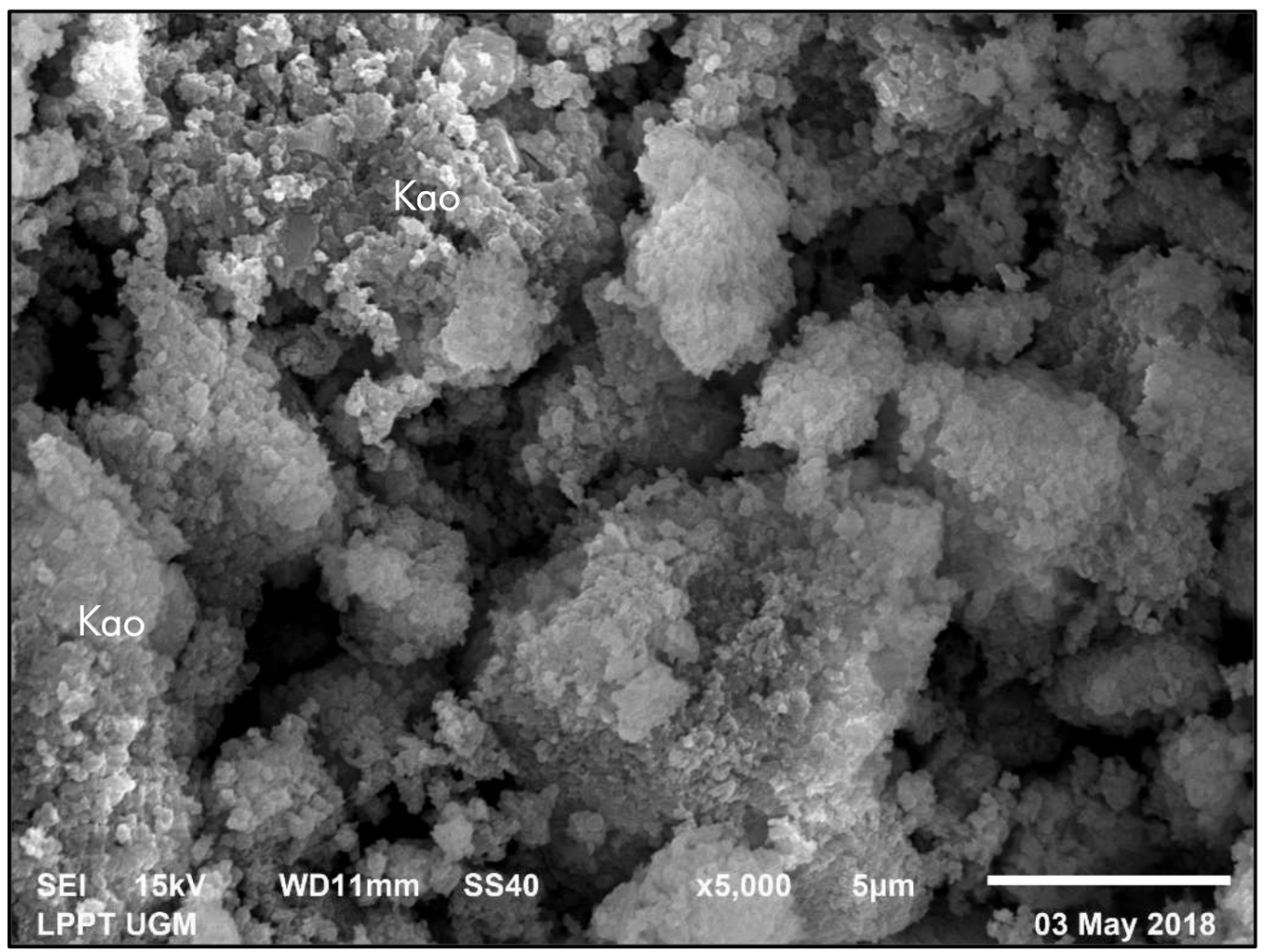

Figure 8. SEM micrograph of the soil sample in the $\mathrm{Gw}-\mathrm{Gw}-\mathrm{Cl}$ system at the middle part $(\mathrm{Kao}=\mathrm{kaolinite})$.

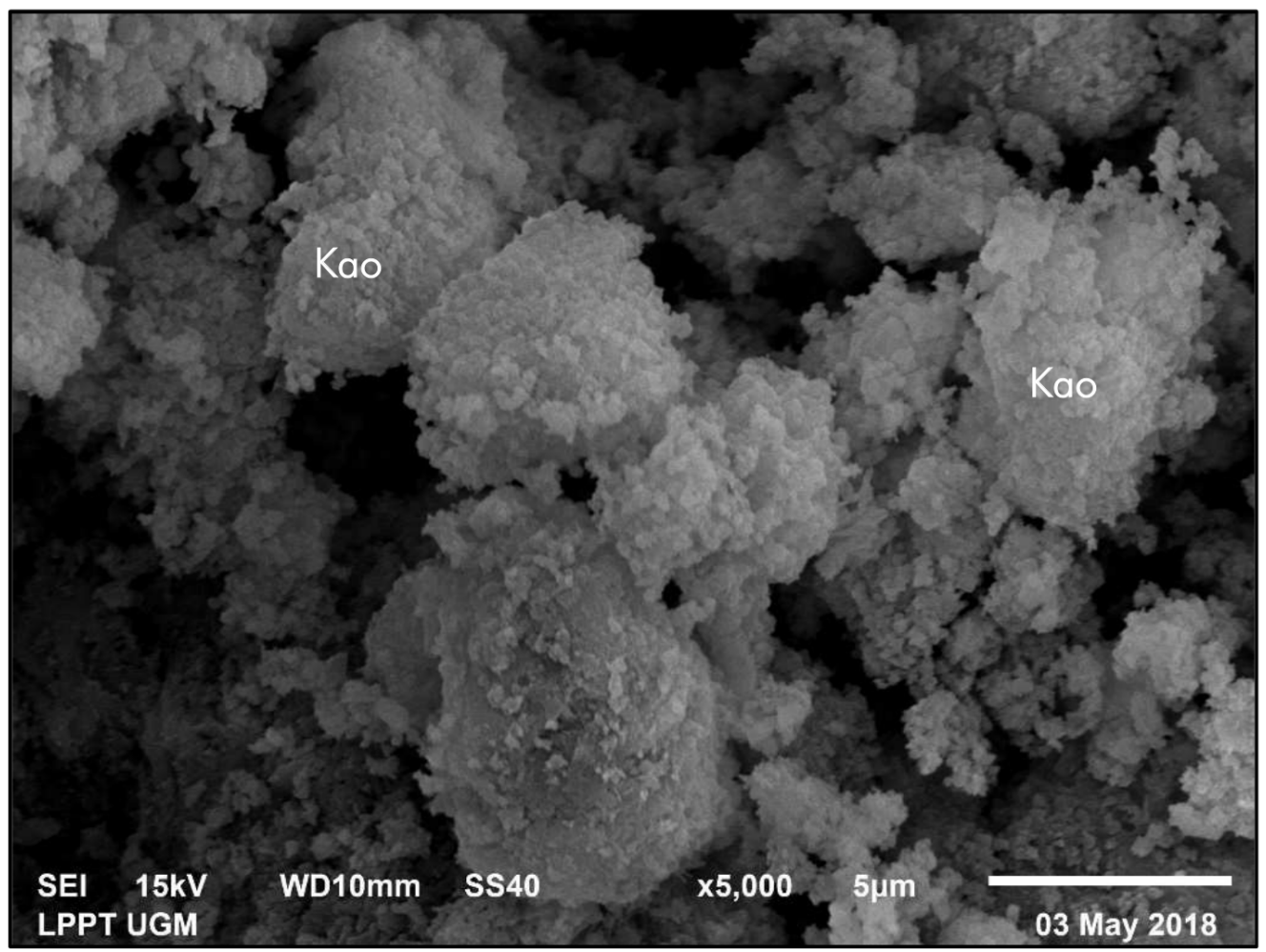

Figure 9. SEM micrograph of the soil sample in the Gw-Gw-Cl system at the cathode part (Kao = kaolinite). 
strengths increased. Both calcium chloride solution and natural groundwater increased the shear strength of the soil samples after the electro-kinetic experiments. However, calcium chloride was found to be more effective in increasing soil shear strength as compared to groundwater. XRD and SEM analyses indicated that there were no mineral changes after electro-kinetic experiments. However, the soil structure changed and became denser. The increased soil strength after electro-kinetic treatment would likely improve stability of natural slopes.

\section{ACKNOWLEDGEMENTS}

The first author would like to thank the ASEAN University Network/Southeast Asia Engineering Education Development Network (AUN/SEED-Net) for the scholarship to pursue master degree in Universitas Gadjah Mada.

\section{REFERENCES}

Alshawabkeh, A.N., (2001), Basics and application of electrokinetic remediation. Handouts prepared for a short course, in Handouts Prepared for a Short Cour se. 2001, Federa University of Rio de Janeiro: Rio de Janeiro. pp. 95.

Black, J.L. and Wektman, A. (2010) Electrokinetic strengthening and repair of slopes. Techanical Note in Ground Engineering, Aprial 2010.
Fauzian, G., (2016) Karakteristik geologi teknik dan zona kemampuan geologi teknik untuk permukiman Desa Purwoharjo dan Gerbosari, Kecamatan Samigaluh, Kabupaten Kulon Progo, Daerah Istimewa Yogyakarta. Undergraduate Thesis, Universitas Gadjah Mada (unpublished).

Justin P. M. and Robert L. P. (2004) Performance of soil stabilization agents, K-TRAN: KU-01-8, Depatment of Teansportation, The University of Kansas.

Malekzadeh, M., Lovisa, J., Sivakugan, N. (2016) An Overview of Electrokinetic Consolodiation of Soils, Geotechanical and Geological Engineering, Springer International Publishing Switzerland 2016.

Mosavat, N. (2014). Electrokinetic Treatment of Fine-grained Soils with Chemical Enhancement Solutions. Dissertation submitted to Griffith University to obtain the Degree of Doctor in Griffith School of Engineering.

Nasim M., Erwin O., and Gary C. (2012) Review of electrokinetic treatment technique for improving the engineering characteristics of low permeable problematic soils, International Journal of Geomate, Vol. 2, No. 2 (SI. No. 4), p 266-272.

Rustamaji, R.M. (2007) Ground Improvement Using Electro-Chemical Injection. Ph.D Thesis.

Thakur L. S, Shah T. K., Shah D. L., Vasavada. D. A. (2011) Strengthening silty soil using electrokinetic grouting, Proceeding of Indian Geotechanical Conference, December 15-17, Kochi, Paper No. H-211, p. 441-444. 